\title{
Triple Layer Antireflection Design Concept for the Front Side of c-Si Heterojunction Solar Cell Based on the Antireflective Effect of nc-3C-SiC:H Emitter Layer
}

\author{
Erick Omondi Ateto, ${ }^{1}$ Makoto Konagai, $^{2}$ and Shinsuke Miyajima ${ }^{1}$ \\ ${ }^{1}$ Department of Physical Electronics, Tokyo Institute of Technology, 2-12-1-NE-17 O-okayama, Meguro-ku, Tokyo 152-8552, Japan \\ ${ }^{2}$ Research Centre for Silicon Nano-Science, Tokyo City University, 8-9-18, Todoroki, Setagaya, Tokyo 158-8586, Japan \\ Correspondence should be addressed to Erick Omondi Ateto; ateto.e.aa@m.titech.ac.jp
}

Received 26 November 2015; Revised 31 January 2016; Accepted 2 February 2016

Academic Editor: Sergey Varlamov

Copyright (C) 2016 Erick Omondi Ateto et al. This is an open access article distributed under the Creative Commons Attribution License, which permits unrestricted use, distribution, and reproduction in any medium, provided the original work is properly cited.

\begin{abstract}
We investigated the antireflective (AR) effect of hydrogenated nanocrystalline cubic silicon carbide (nc-3C-SiC:H) emitter and its application in the triple layer AR design for the front side of silicon heterojunction (SHJ) solar cell. We found that the nc-3C-SiC:H emitter can serve both as an emitter and antireflective coating for SHJ solar cell, which enables us to realize the triple AR design by adding one additional dielectric layer to normally used SHJ structure with a transparent conductive oxide (TCO) and an emitter layer. The optimized SHJ structure with the triple layer AR coating ( $\mathrm{LiF} / \mathrm{ITO} / \mathrm{nc}-3 \mathrm{C}-\mathrm{SiC}: \mathrm{H})$ exhibit a short circuit current density $\left(J_{\mathrm{sc}}\right)$ of $38.65 \mathrm{~mA} / \mathrm{cm}^{2}$ and lower reflectivity of about $3.42 \%$ at wavelength range of $300 \mathrm{~nm}-1000 \mathrm{~nm}$.
\end{abstract}

\section{Introduction}

Crystalline silicon (c-Si) wafer based solar cell is currently the dominant technology in the market with a market share of more than $80 \%$ and is expected to remain the most prominent PV technology for the next decade. The recent research focus in c-Si wafer based solar cell is to increase the energy conversion efficiency and reduce the cost to make it more competitive with the conventionally used fossil fuel. In this context, SHJ solar cell technology has been demonstrated to be a promising candidate for high conversion efficiency solar cells beyond $25 \%$.

A typical example is the $\mathrm{SHJ}$ solar cell with the back contact configuration which has achieved up to $25.6 \%$ efficiency [1]. A high $V_{\text {oc }}$ of $0.750 \mathrm{~V}$ has also been achieved on n-type c-Si wafer using amorphous silicon $(\mathrm{a}-\mathrm{Si}: \mathrm{H})$ as the emitter and back surface field [2]. This higher $V_{o c}$ is due to good passivation quality of intrinsic (i) a-Si:H used for passivation. However, the loss analysis of these SHJ solar cells indicates that there is nonnegligible $J_{\mathrm{sc}}$ loss attributed to the front a-Si:H emitter layer [3]. This is because charge carrier generated from a considerable amount of shorter wavelength photon of the solar spectrum absorbed in a$\mathrm{Si}: \mathrm{H}$ emitter layer instantaneously recombine due to high defect density in the layer. Another disadvantage of a-Si:H is its high refractive index, which is similar to that of c$\mathrm{Si}$. This leads to high reflection at the interface between a$\mathrm{Si}: \mathrm{H}$ and transparent conductive oxide. To solve this problem, relatively wider band-gap material with lower refractive index and low absorption coefficient should be used. For this end, hydrogenated nanocrystalline cubic silicon carbide (nc-3C$\mathrm{SiC}: \mathrm{H})$ has been shown to be a promising material as an emitter layer for the heterojunction solar cell [4-8].

One way to reduce the cost of $\mathrm{c}-\mathrm{Si}$ solar cell is to reduce the wafer thickness used to fabricate the solar cells. It is estimated that the wafer processing accounts for approximately $50 \%$ of the solar cell cost. Thinner wafers can therefore play a fundamental role in the further reduction of the cost of solar cell [9]. SHJ solar cell structure is suitable for thinner c-Si wafer application [10]. The main disadvantage of thin c-Si wafer based SHJ solar cell is the poor absorption performance in the red and NIR part of the solar spectrum, which leads to lower $J_{s c}$. Thus excellent antireflection and light trapping is a requirement for such cells. In the state-of-the-art SHJ solar 


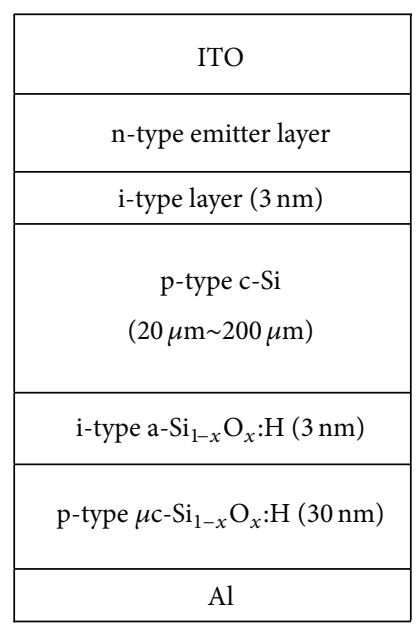

(a)

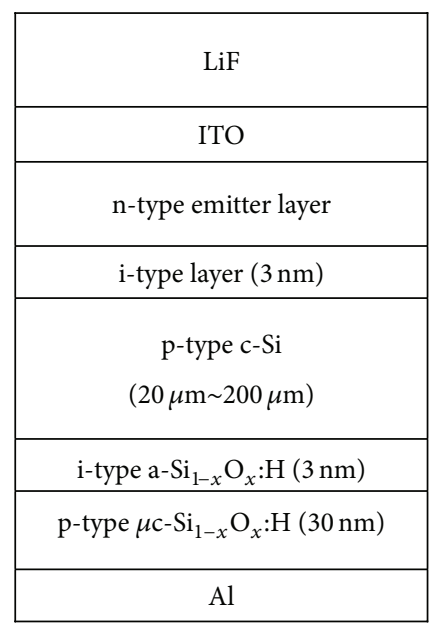

(b)

Figure 1: (a) The schematic structure of the c-Si heterojunction structure with single AR coating. (b) Heterojunction structure with additional layer of $\mathrm{LiF}$.

cell, antireflection and light trapping is realized by pyramidal texturing that can be achieved through alkali etching [1113]. This combined with the transparent conductive oxide (TCO) leads to a very low reflectance and also increases the optical path length for all photons in the solar spectrum [11, 12, 14-17]. However such pyramidal texturing requires micron-size features that are inapplicable to novel thin wafers based SHJ solar cell since they become very fragile and delicate to handle. Moreover greater surface area increases carrier recombination in the surface between thin film and cSi wafer, which has a detrimental effect on the $V_{\text {oc }}$. Therefore other approaches for highly efficient antireflection and light trapping schemes have to be considered for thinner planar cSi wafers based solar cell.

For light trapping, advanced methods have been proposed to enhance light absorption in thinner wafers based solar cell [18-22]. Regrettably, all these light trapping schemes encounter some inherent limitation for use especially in the front side of the SHJ solar cell. Use of nanoparticles for the front emitter still has to be embedded in dielectrics layer to improve their light trapping effect. The nanoparticles at the front side also suppress the absorption of blue/green region light into the c-Si due to interference effect thereby leading to a decrease in $J_{\text {sc }}$ for SHJ solar [23]. This suppression can only be avoided by locating nanoparticles array at the rear side of the SHJ solar cell to scatter and trap poorly absorbed longer wavelength light of the solar spectrum [24]. Other advanced light trapping schemes such as grating produced via nanoimprint lithography or self-assembled hexagonal sphere gratings that have been proposed are industrially incompatible and also can only be applied at the rear side of the structure. Therefore for front side of SHJ solar cell, multi-AR coating that can be used in conjunction with these advanced light trapping schemes need to be considered.

In this paper, we investigated a triple layer AR concept for the front side of SHJ solar cell that capitalizes on the antireflective effect of nc-3C-SiC:H emitter layer. Use of emitter layer for AR effect has not been investigated before. This paper, therefore, provides a foundation for the design of the triple layer AR using transparent emitter layer and only one additional dielectric layer to the normally used SHJ structure. The optimization is conducted using device simulator, AFORS-HET [25]. Wide band-gap nc-3C-SiC:H with low absorption coefficients and refractive indices between $\mathrm{c}$ $\mathrm{Si}$ and ITO therefore can serve both as an emitter and AR coating. In this paper lithium fluoride $(\mathrm{LiF})$ is used as the additional layer; however, $\mathrm{MgF}_{2}, \mathrm{Al}_{2} \mathrm{O}_{3}$, and $\mathrm{SiO}_{2}$ also show very promising results $[26,27]$. This work focuses only on the reflection and parasitic reduction at the front side of SHJ solar cell. To validate our analysis we compared our simulation result for our structure with the conventionally used a-Si:H emitter.

\section{Cell Structure and Optical Model}

2.1. SHJ Solar Cell Structure. The SHJ solar cell structure used in the simulation is shown in Figures 1(a) and 1(b). The difference of these two is the front side structure. Figure 1(a) is the conventional structure consisting of an intrinsic (i) type buffer layer, emitter layer, and indium tin oxide (ITO) TCO layer at the front side. Figure $1(\mathrm{~b})$ is the structure with additional layer of LiF dielectric layer, which henceforth will be called a triple AR coating structure. For the emitter layer, n-type a-Si:H and n-type nc-3C-SiC:H emitter layers are used. Intrinsic hydrogenated amorphous silicon (i-type a$\mathrm{Si}: \mathrm{H})$ and intrinsic hydrogenated amorphous silicon carbide (i-type a-SiC:H) buffer layer are used as the i-type layer for a-Si:H and nc-3C-SiC:H emitter SHJ structure, respectively. For the rear side, intrinsic amorphous silicon oxide (itype a-Si $\left.\mathrm{i}_{1-x} \mathrm{O}_{x}: \mathrm{H}\right)$ and $\mathrm{p}$-type hydrogenated microcrystalline silicon oxide ( $\mathrm{p}$-type $\mu \mathrm{c}$ - $\mathrm{Si}_{1-x} \mathrm{O}_{x}: \mathrm{H}$ ) were used as the back surface field (BSF). Aluminum (Al) was used as the front and rear electrode. The triple layer AR coating has been optimized on $200 \mu \mathrm{m}$ thick silicon wafer. However, we varied 


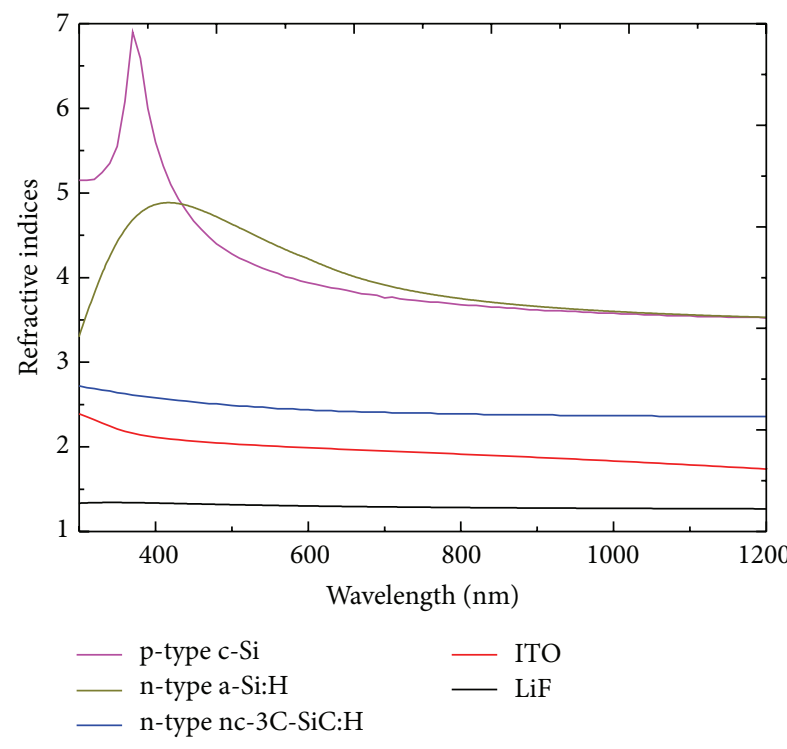

(a)

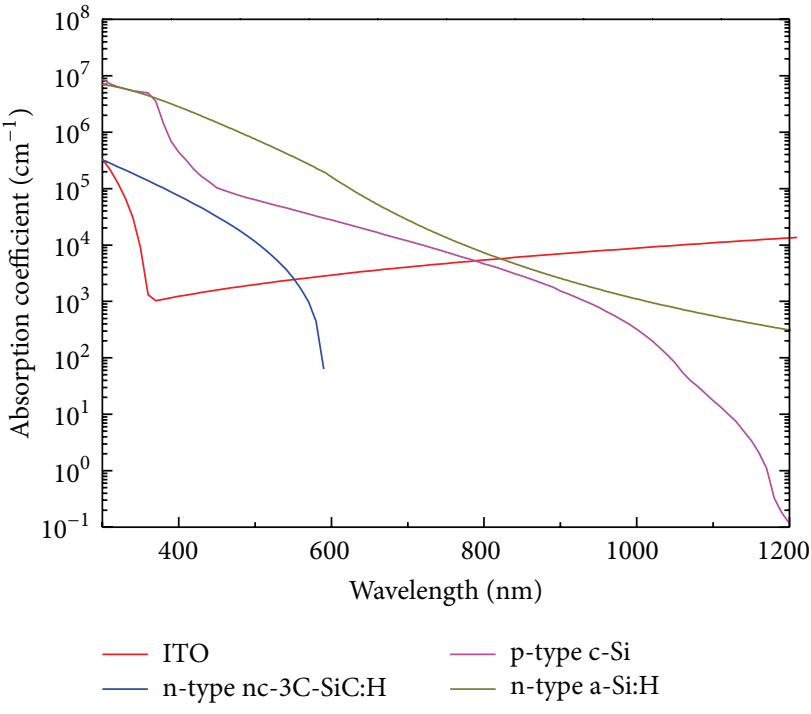

(b)

Figure 2: (a) The refractive indices of c-Si, emitter layers, ITO, and LiF used in the simulation. (b) The absorption coefficient of c-Si, emitter layers, ITO, and LiF used in the simulation.

the thickness of the silicon from $200 \mu \mathrm{m}$ to $20 \mu \mathrm{m}$ to ascertain the effect of $\mathrm{c}$-Si thickness on the reflection especially at longer wavelength.

2.2. Optical Parameters of the Materials. The optical refractive indices and absorption coefficients of the materials used are shown in Figure 2. The complex refractive indices of $n-$ type nc-3C-SiC:H, i-type a-SiC:H, i-type a-Si $i_{1-x} \mathrm{O}_{x}: \mathrm{H}$, p-type $\mu \mathrm{c}-\mathrm{Si}_{1-x} \mathrm{O}_{x}: \mathrm{H}$, ITO, and $\mathrm{LiF}$ were obtained from Woollam spectroscopic ellipsometry measurements of the individual layers deposited on c-Si wafers.

The n-type nc-3C-SiC:H emitter was deposited by very high frequency plasma enhanced chemical vapor deposition (VHF-PECVD) method with an excitation frequency of $60 \mathrm{MHz}$. The p-type $\mu c-\mathrm{Si}_{1-x} \mathrm{O}_{x}: \mathrm{H}$ and $\mathrm{i}$-type $\mathrm{a}-\mathrm{Si}_{1-x} \mathrm{O}_{x}: \mathrm{H}$ were deposited by RF-PECVD (13.56 MHz) and VHFPECVD, respectively. The LiF layer was deposited by thermal evaporation. ITO was deposited by radio frequency (RF) magnetron sputtering. The details of the nc-3C-SiC:H emitter deposition, ITO deposition, and the overall solar cell fabrication process are reported in the previous publications $[5,7,28,29]$. The complex refractive index included in the AFORS-HET package for n- and i-type a-Si:H, p-type c-Si, and $\mathrm{Al}$ electrode were used.

2.3. Optical Analysis Method. One of the useful figures of merit for the optimization of the ARC design is the weighted reflectance $R_{\mathrm{av}}$ shown as follows [30]:

$$
R_{\mathrm{av}}(\%)=\frac{\int_{300}^{1200} \emptyset(\lambda) R(\lambda) \mathrm{d} \lambda}{\int_{300}^{1200} \emptyset(\lambda) \mathrm{d} \lambda} \times 100 \%,
$$

where $R(\lambda)$ is the simulated reflectance of the solar cell and $\emptyset(\lambda)$ is the photo flux density of the AM 1.5 solar spectrum, which is adopted as the illuminating source in the simulation, with a wavelength range $300 \mathrm{~nm}-1200 \mathrm{~nm}$ in $1 \mathrm{~nm}$ step.

Conventionally, weighted reflectance has been used as the only merit for optimization of the AR coating. However, due to the parasitic absorption losses in ITO layer, buffer layer, emitter layer, and rear metal electrode layer, it is very crucial to also consider absorbance in $\mathrm{c}-\mathrm{Si}$, to achieve more accurate design of AR coating as will be shown later. In the case of start-of-the art c-Si solar cells with well-passivated front and rear surface, the absorbance in $\mathrm{c}-\mathrm{Si}$ is what contributes to the photo current density. The absorbance in $\mathrm{c}$-Si can be evaluated using the weighted average absorbance $\left(A_{\mathrm{av}}\right)$ as shown in

$$
A_{\mathrm{av}}(\%)=\frac{\int_{300}^{1200} \emptyset(\lambda) A_{\mathrm{c}-\mathrm{Si}}(\lambda) \mathrm{d} \lambda}{\int_{300}^{1200} \emptyset(\lambda) \mathrm{d} \lambda} \times 100 \%,
$$

where $A_{c-S i}(\lambda)$ is the absorbance in $\mathrm{c}-\mathrm{Si}$ in each wavelength. This equation can also be used to calculate absorption in other layers of the SHJ structure. The denominator for (1) and (2) calculates a total photon flux of $2.9 \times 10^{21}$ (photons $\mathrm{s}^{-1} \mathrm{~m}^{-2}$ ), which corresponds to photo current density of $46.46 \mathrm{~mA} / \mathrm{cm}^{2}$, at an internal quantum efficiency of 1 and reflectance of 0 . Using $A_{\mathrm{c}-\mathrm{Si}}$, the photo current density due to absorbance in $\mathrm{C}$-Si can therefore be calculated as shown in

$$
J_{\mathrm{c}-\mathrm{Si}}\left(\frac{\mathrm{mA}}{\mathrm{cm}^{2}}\right)=46.46 \times \mathrm{A}_{\mathrm{c}-\mathrm{Si}}
$$

This equation can also be used to calculate the parasitic current losses incurred in TCO, emitter, front i-type and rear metal electrode layers. 


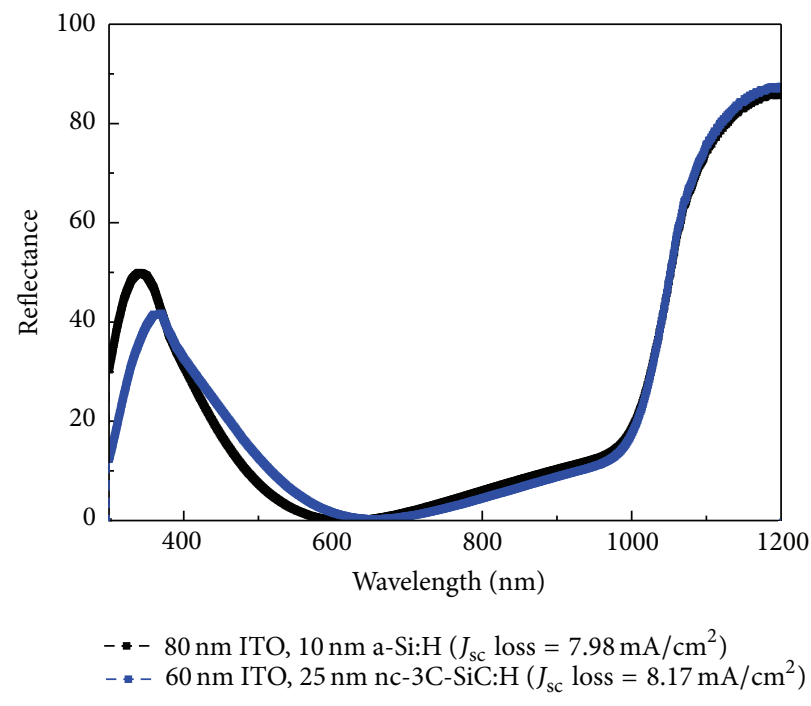

(a)

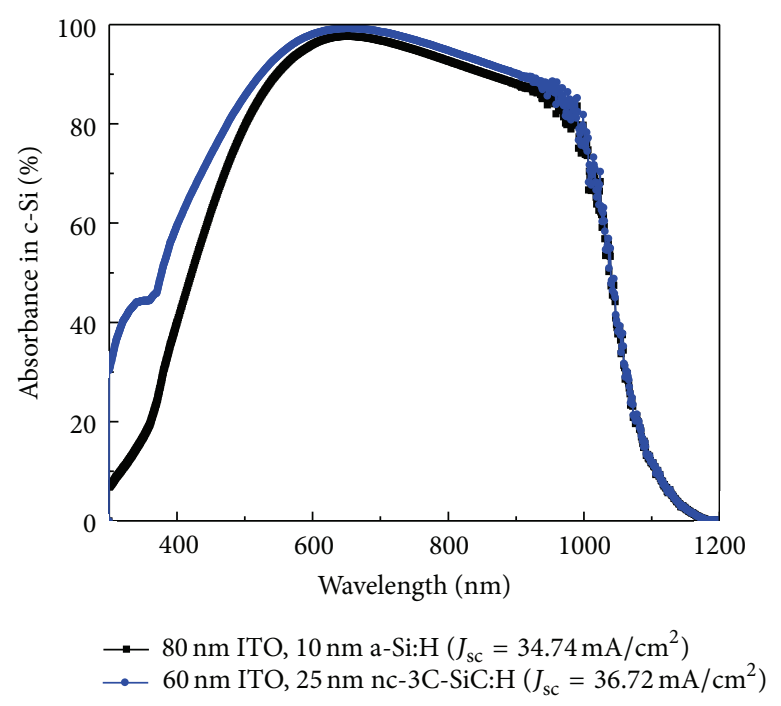

(b)

Figure 3: (a) The reflectance spectra for SHJ solar cells with nc-3C-SiC:H emitter and a-Si:H emitter with a single AR coating (b). The corresponding absorbance. The absorbance spectra are the absorbance in c-Si layer in the solar cells.

\section{Result and Discussion}

For improving conversion efficiency, it is important for a c-Si solar cell to have minimal reflectance over the entire visible and near infrared spectrum. This can easily be achieved on SHJ solar cell by using textured wafer combined with single AR coating of TCO; the TCO also serves as a lateral transport medium for photo generated carriers to metal finger contact. In contrast to the textured wafers, a single AR coating is not enough for planar wafers. In the case of the single AR coating, there is the wavelength, which gives the minimum reflectivity, and low reflectivity is only obtained near the wavelength. On the other hand, the local minimum of the reflectivity is obtained at multiple wavelengths for multiple AR coating, which can widen the wavelength range for good antireflective performance.

3.1. Optical Simulation of the SHJ with Only ITO AR Coating. Figure 3 shows the simulated reflectance and absorbance spectra of the SHJ solar cells with optimum single AR coating of ITO. We calculated the spectra for SHJ solar cells with nc3C-SiC:H emitter and a-Si:H emitter. The optimal thicknesses of a-Si:H and nc-3C-SiC:H emitter were $10 \mathrm{~nm}$ and $25 \mathrm{~nm}$, respectively. In the AR coating design, the thickness of the coating material is important to minimize the reflection. In our simulations, the optimal thicknesses of ITO obtained for a-Si:H and nc-3C-SiC:H SHJ structures were $80 \mathrm{~nm}$ and $60 \mathrm{~nm}$, respectively.

The reflectance spectra of the SHJ solar cell with nc-3C$\mathrm{SiC}: \mathrm{H}$ emitter closely resemble the a-Si:H emitter counterpart with a slight variation at wavelength range of $300 \mathrm{~nm}-$ $600 \mathrm{~nm}$. This variation is due to the difference in parasitic absorption and the thicknesses of the emitter layer and ITO layer of the structures. For both structures, minimum reflectance is observed at one certain wavelength $\lambda_{\min }$. The $\mathrm{SHJ}$ solar cell with nc-3C-SiC:H emitter shows the minimum reflectance is obtained at $\lambda_{\text {min }}=653 \mathrm{~nm}$ while $\lambda_{\text {min }}$ is found to be $635 \mathrm{~nm}$ for the SHJ solar cell with a-Si:H emitter.

For a single AR coating, based on the reflectance spectra of the SHJ solar cell with nc-3C-SiC:H emitter shown in Figure 3(a), it cannot be explicitly deduced whether nc-3C$\mathrm{SiC}: \mathrm{H}$ demonstrates an antireflective effect. However, it is worth noting that there is a minimum reflectance observed at wavelength lower than $300 \mathrm{~nm}$ which contributes to relatively lower reflectance in the range of $300 \mathrm{~nm}$ to $400 \mathrm{~nm}$ as compared to the $\mathrm{SHJ}$ solar cell with a-Si:H emitter.

The total reflectance for the SHJ solar cell with a-Si:H emitter was found to be $17.2 \%$ corresponding to a reflected $J_{\text {sc }}$ loss of $7.98 \mathrm{~mA} / \mathrm{cm}^{2}$. While for the SHJ solar cell with nc-3C-SiC:H emitter was $17.6 \%$ corresponding to a reflected $J_{\text {sc }}$ loss of $8.17 \mathrm{~mA} / \mathrm{cm}^{2}$. Although the reflectance spectra for the two structures are comparable, with only slight variation at wavelength range $300 \mathrm{~nm}-600 \mathrm{~nm}$, the absorbance in c-Si exhibited a significant difference. This difference is attributed to the absorption loss in the emitter layer. The nc-3C$\mathrm{SiC}: \mathrm{H}$ emitter significantly boosts light absorption in c$\mathrm{Si}$ at wavelength range $300 \mathrm{~nm}-600 \mathrm{~nm}$ due to its higher transmittance compared to that of the a-Si:H emitter. In case of the a-Si:H emitter, the parasitic absorption in the a-Si:H emitter reduces the short wavelength $(300 \mathrm{~nm}-600 \mathrm{~nm})$ light that reaches the $\mathrm{c}$-Si. This has a detriment effect on the overall $J_{\text {sc }}$ that can be obtained from the SHJ solar cell.

It should be also noted that even though the optimum thickness of nc-3C-SiC:H emitter $(25 \mathrm{~nm})$ is more than twice the optimum thickness of a-Si:H emitter $(10 \mathrm{~nm})$, the absorbance in a-Si:H emitter is evidently high. The absorbance in the a-Si:H emitter and nc-3C-SiC:H emitter is $4 \%$ and $0.42 \%$, respectively. This absorbance in a-Si:H emitter contributes $1.86 \mathrm{~mA} / \mathrm{cm}^{2} J_{\mathrm{sc}}$ loss as compared to only a $J_{\mathrm{sc}}$ loss of $0.2 \mathrm{~mA} / \mathrm{cm}^{2}$ for nc-3C-SiC:H emitter. In addition, other parasitic absorption incurred in i-type buffer 
TABLE 1: Comparative result of the total reflectance and the total absorbance in each layer with different AR coating schemes and emitter layer for flat SHJ solar cell. The thicknesses of AR and emitter are optimized values.

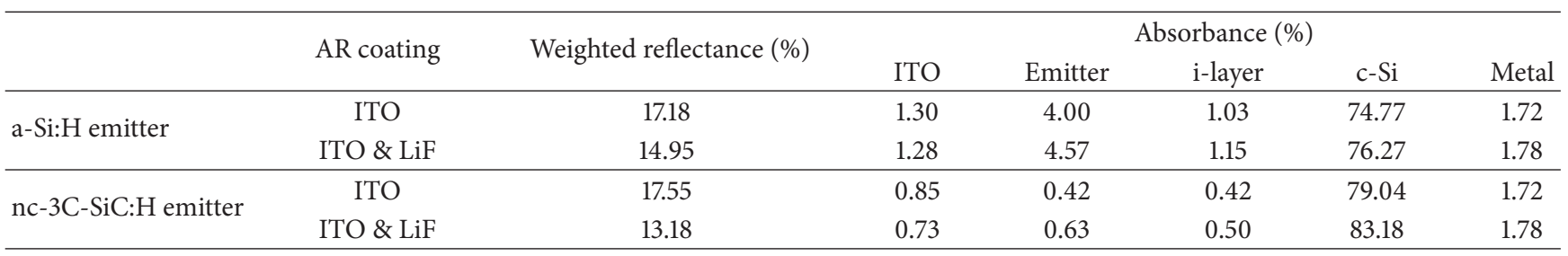

layer and ITO layers of the two structures also is attributed to lower $J_{\mathrm{sc}}$. The absorbance in ITO was $1.3 \%$ and $0.84 \%$ for SHJ solar cells with a-Si:H and nc-3C-SiC:H emitter, respectively. These correspond to a $J_{\mathrm{sc}}$ loss of $0.39 \mathrm{~mA} / \mathrm{cm}^{2}$ and $0.60 \mathrm{~mA} / \mathrm{cm}^{2}$ in ITO for SHJ with nc-3C-SiC:H and a$\mathrm{Si}: \mathrm{H}$ emitter, respectively. The $J_{\mathrm{sc}}$ loss in the i-type buffer layer of a-Si:H and a-SiC:H was found to be $0.48 \mathrm{~mA} / \mathrm{cm}^{2}$ and $0.2 \mathrm{~mA} / \mathrm{cm}^{2}$, respectively. However, as Holman et al. duly noted, $30 \%$ of the aforementioned i-layer $J_{s c}$ losses can still contribute to $J_{\mathrm{sc}}$ [3]. The $J_{\mathrm{sc}}$ loss due to rear electrode was about $0.80 \mathrm{~mA} / \mathrm{cm}^{2}$ for both structures. From this finding, it should be therefore emphasized that only minimizing reflectance does not guarantee maximization of the absorbance in $\mathrm{c}-\mathrm{Si}$. The parasitic absorption especially at the emitter and TCO layer also need to be taken into account when designing AR coating. Overall, $J_{\mathrm{sc}}$ calculated from absorbance in c-Si shown in Table 1 for SHJ solar cells with a-Si:H emitter with single AR coating was $34.74 \mathrm{~mA} / \mathrm{cm}^{2}$ while that of SHJ solar cell with nc-3C-SiC:H emitter was $36.72 \mathrm{~mA} / \mathrm{m}^{2}$.

\subsection{Optical Simulations for SHJ Solar Cells with an Additional} LiF Dielectric Layer. As previously mentioned, a single layer AR coating only has a good antireflection effect for a single wavelength while when multiple AR coating is used, good antireflection effect can be achieved within a wide spectrum. A set of optimized and well-designed multilayer AR coating can therefore be an effective way to improve the optical absorption of the solar cell in thin planar wafers. The common method employed for the design of multiple AR coatings on silicon is transfer matrix method [31]. Bouhafs et al. designed a hypothetical triple layer AR coating for a silicon substrate [32]. Their calculation yielded hypothetical materials with optimum refractive indices 1.4, 1.97, and 2.78 for outer layer, medium layer, and inner layer. The optimum thicknesses they found were thicknesses $104 \mathrm{~nm}, 55 \mathrm{~nm}$, and $51 \mathrm{~nm}$ for outer layer, medium layer, and inner layer, respectively. Bett et al. also calculated front side antireflection concept for silicon solar cell using $\mathrm{TiO}_{2}, \mathrm{SiN}_{x} \mathrm{O}_{y}$, and $\mathrm{MgF}_{2}$ where $\mathrm{TiO}_{2}$ is the inner layer with thickness of $52 \mathrm{~nm}$ [33]. In both cases, they found that the inner layer has to be over $40 \mathrm{~nm}$ thick to achieve a good antireflective effect.

Our approach is to use emitter layer as the inner layer of the triple antireflection design concept. Conventionally, in silicon heterojunction solar cells, the emitter thickness tends to be in the range of $5 \mathrm{~nm}$ to $10 \mathrm{~nm}$ especially in the case of a-Si:H where parasitic absorption has an adverse effect on $J_{\mathrm{sc}}$. This does not give enough room for the design of the AR coating. On the contrary, due to its transparency at shorter wavelength, nc-3C-SiC:H emitter thickness can be increased up to $40 \mathrm{~nm}$ without having any parasitic absorption effect. Moreover, as shown in Figure 2(a), nc-3C$\mathrm{SiC}: \mathrm{H}$ has a refractive index of about 2.72 at $300 \mathrm{~nm}$ to 2.37 at $1200 \mathrm{~nm}$, therefore making it a close to ideal material for the inner layer of the AR coating as designed by Bouhafs et al.

To investigate the antireflective effect of the emitter layer, we optimized the thicknesses of LiF and ITO and the emitter (nc-3C-SiC:H and a-Si:H) layers that yield minimum total reflectance and maximum absorbance in c-Si calculated using (1) and (2). The optimum thicknesses of ITO and LiF for $10 \mathrm{~nm}$ a-Si:H emitter SHJ structure were found to be $70 \mathrm{~nm}$ and $90 \mathrm{~nm}$, respectively, while those of $40 \mathrm{~nm} \mathrm{nc}-3 \mathrm{C}-\mathrm{SiC}: \mathrm{H}$ emitter SHJ structure were $60 \mathrm{~nm}$ and $100 \mathrm{~nm}$, respectively. With optimum LiF and ITO thicknesses, emitter layer is varied and $J_{\mathrm{sc}}$ loss due to total reflection and emitter parasitic absorption is calculated. Figures 4(a) and 4(b) show the emitter $J_{\mathrm{sc}}$ loss due to parasitic absorption and reflection as a function of the emitter thickness. For a-Si:H emitter, $J_{\text {sc }}$ loss due to parasitic absorption increases linearly from $1.76 \mathrm{~mA} / \mathrm{cm}^{2}$ for $8 \mathrm{~nm}$ thick a-Si:H to $4.89 \mathrm{~mA} / \mathrm{cm}^{2}$ for $30-\mathrm{nm}$ thick a$\mathrm{Si}: \mathrm{H}$ emitter. This increase in parasitic absorption in a-Si:H emitter concurs with the results reported by Holman et al. [3]. For nc-3C-SiC:H emitter, $J_{\mathrm{sc}}$ loss due to parasitic absorption also increases linearly, although extremely small, from $0.12 \mathrm{~mA} / \mathrm{cm}^{2}$ to $0.36 \mathrm{~mA} / \mathrm{cm}^{2}$. Moreover, in Figure 4, while reflectance $J_{\mathrm{sc}}$ loss in $\mathrm{SHJ}$ solar cell with a-Si:H emitter increases with emitter thickness, SHJ solar cell with nc-3C$\mathrm{SiC}: \mathrm{H}$ emitter exhibits an opposite behavior as anticipated for an antireflective emitter. This explicitly demonstrates the antireflective effect of nc-3C-SiC:H emitter layer. This also revealed that nc-3C-SiC:H emitter can be used to design a triple layer AR coating concept for the front side of SHJ solar cell. On the other hand, a-Si:H emitter cannot be used in the AR coating design; therefore two more layers of dielectrics have to be deposited to achieve a triple layer AR coating.

Figures 5(a) and 5(b) show the reflectance spectra and absorbance in c-Si comparing SHJ solar cell with nc-3CSiC:H emitter with only ITO and with ITO and an additional $\mathrm{LiF}$ layer. For these structures we used an optimum thickness of $60 \mathrm{~nm}$ for ITO. It is observed that SHJ solar cell with nc-3C-SiC:H emitter with $\mathrm{LiF}$ and ITO exhibits a local minimum reflectance at three distinct wavelengths $\lambda_{\text {min }}=320 \mathrm{~nm}, \lambda_{\text {min }}=520 \mathrm{~nm}$, and $\lambda_{\text {min }}=900 \mathrm{~nm}$ (zero reflectance). Therefore low reflection can be achieved over a broad wavelength range of the visible light. As shown in Figure 5(a) the $J_{\text {sc }}$ loss due to reflection is remarkably reduced 


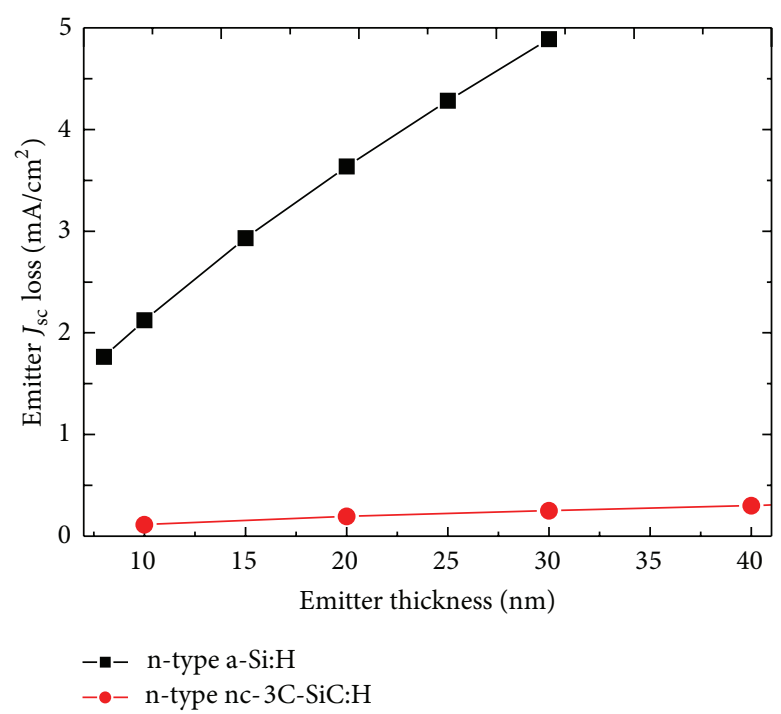

(a)

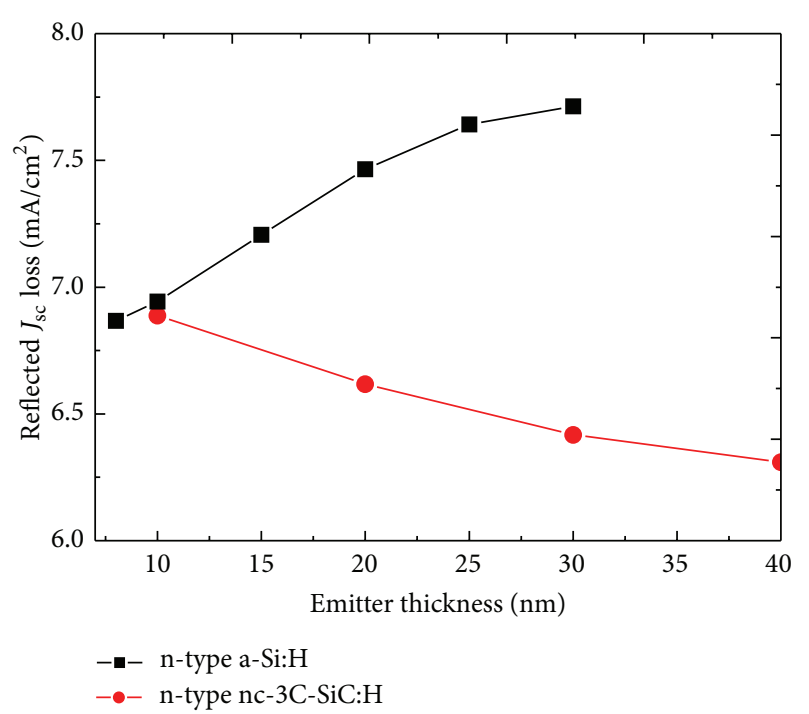

(b)

FIgURE 4: (a) The emitter current density loss as a function of the emitter thickness of the SHJ solar cell (b). The reflected current density loss as a function of emitter thickness for SHJ solar cell.

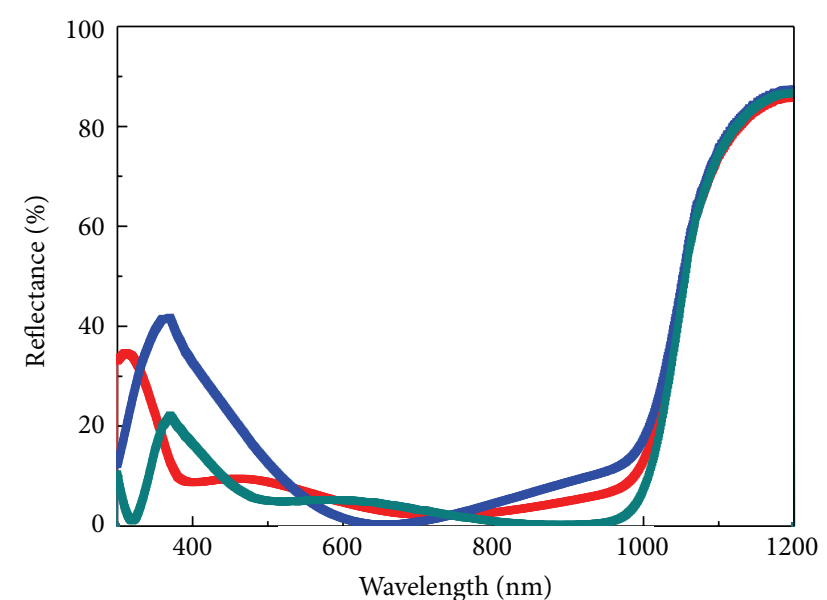

$=100 \mathrm{~nm} \mathrm{LiF}, 60 \mathrm{~nm}$ ITO, $40 \mathrm{~nm}$ nc-3C-SiC:H $\left(J_{\mathrm{sc}}\right.$ loss $\left.=6.12 \mathrm{~mA} / \mathrm{cm}^{2}\right)$
$=-90 \mathrm{~nm} \mathrm{LiF}, 60 \mathrm{~nm}$ ITO, $8 \mathrm{~nm}$ a-Si:H $\left(J_{\mathrm{sc}}\right.$ loss $\left.=6.94 \mathrm{~mA} / \mathrm{cm}^{2}\right)$
$=60 \mathrm{~nm} \mathrm{ITO}, 25 \mathrm{~nm}$ nc-3C-SiC:H $\left(J_{\mathrm{sc}}\right.$ loss $\left.=8.17 \mathrm{~mA} / \mathrm{cm}^{2}\right)$

(a)

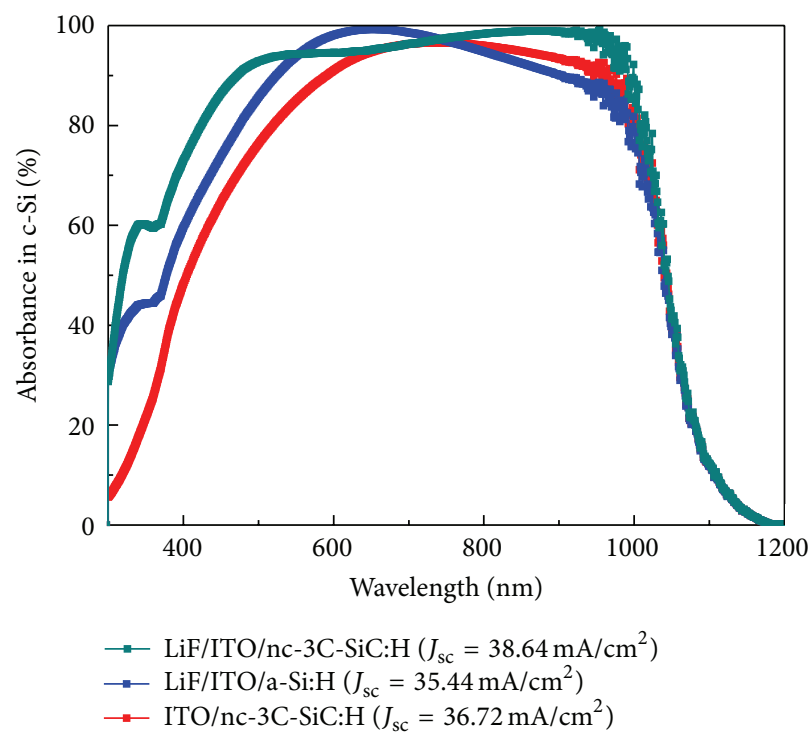

(b)

FIGURE 5: (a) The reflectance spectra on three SHJ solar cells with nc-3C-SiC:H emitter with only ITO, with ITO and LiF dielectric, and SHJ solar cell with a-Si:H emitter, ITO, and LiF dielectric. (b) The corresponding absorbance in c-Si of those SHJ structures.

from $8.17 \mathrm{~mA} / \mathrm{cm}^{2}$ to $6.12 \mathrm{~mA} / \mathrm{cm}^{2}$ for nc-3C-SiC:H emitter when $\mathrm{LiF}$ is used. This reduction in $J_{\mathrm{sc}}$ loss due to triple layer AR coating leads to high $J_{\mathrm{sc}}$. The corresponding total weighted reflectance is shown in Table 1 . On the contrary, $J_{\text {sc }}$ loss is reduced by $1.04 \mathrm{~mA} / \mathrm{cm}^{2}$ for the case of a-Si:H emitter. The $J_{s c}$ for SHJ with nc-3C-SiC:H emitter therefore had an appreciable increase by $1.92 \mathrm{~mA} / \mathrm{cm}^{2}$ when $\mathrm{LiF}$ and ITO are used. While for a-Si:H emitter it is only increased by $0.7 \mathrm{~mA} / \mathrm{cm}^{2}$ when $\mathrm{LiF}$ and ITO are used. Overall, our triple layer AR coating structure achieved appreciable $J_{\mathrm{sc}}$ of $38.65 \mathrm{~mA} / \mathrm{cm}^{2}$ for optimum thickness of $40 \mathrm{~nm} \mathrm{nc}-3 \mathrm{C}-\mathrm{SiC}: \mathrm{H}$,
$50 \mathrm{~nm}$ ITO, and $100 \mathrm{~nm} \mathrm{LiF}$. This result does not take into account the shading loss due to the front electrode.

As shown in Table 1, the total reflectance for nc-3C-SiC:H emitter can be reduced from $17.5 \%$ to $13.2 \%$. It should be noted here that the triple layer antireflection coating only reduces reflectance at the front side of the SHJ solar cell. As can be seen in the reflectance spectra shown in Figure 5(a), higher reflection is observable at longer wavelength $(\lambda>$ $1000 \mathrm{~nm}$ ). To precisely ascertain the effect of triple layer antireflection coating, we calculated the weighted reflectance for spectrum with a wavelength range $(300 \mathrm{~nm}-1000 \mathrm{~nm})$. 
TABLE 2: Comparative result of the total reflectance and the total absorbance in each layer with different AR coating schemes and emitter layer for flat SHJ solar cell. The thicknesses of AR coating and emitter layers are optimized values.

\begin{tabular}{lcccc}
\hline & $\begin{array}{c}\text { Reflected flux } \\
(\%)\end{array}$ & $\begin{array}{c}\text { Current loss due to reflected } \\
\text { flux }\left(\mathrm{mA} / \mathrm{cm}^{2}\right)\end{array}$ & $\begin{array}{c}\text { Absorbance }(\%) \text { in } \\
\mathrm{c}-S i\end{array}$ & $\begin{array}{l}J_{\text {sc }}\left(\mathrm{mA} / \mathrm{cm}^{2}\right) \\
\text { ITO/nc-3C-SiC:H }\end{array}$ \\
Glass/ITO/nc-3C-SiC:H & 17.58 & 8.17 & 79.07 & 36.73 \\
$\mathrm{LiF}(100 \mathrm{~nm}) / \mathrm{ITO} / \mathrm{nc}-3 \mathrm{C}-\mathrm{SiC}: \mathrm{H}$ & 18.34 & 8.52 & 78.13 & 36.30 \\
Glass/LiF $(10 \mathrm{~nm}) / \mathrm{ITO} / \mathrm{nc}-3 \mathrm{C}-\mathrm{SiC}: \mathrm{H}$ & 13.58 & 6.31 & 82.63 & 38.65 \\
Glass/Al $\mathrm{O}_{3} / \mathrm{ITO} / \mathrm{nc}-3 \mathrm{C}-\mathrm{SiC}: \mathrm{H}$ & 17.15 & 7.97 & 79.17 & 36.78 \\
\hline
\end{tabular}

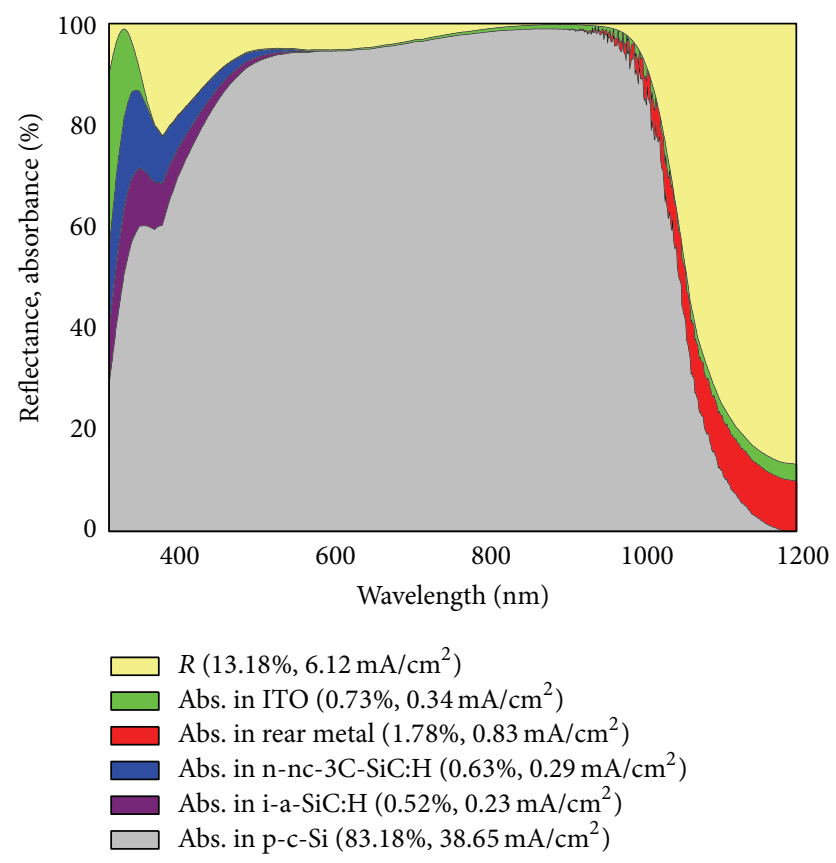

FIGURE 6: The absorbance at each layer of SHJ solar cell with nc-3C$\mathrm{SiC}: \mathrm{H}$ emitter, ITO, and $\mathrm{LiF}$ dielectric AR coating.

The total reflectance for nc-3C-SiC:H emitter with only ITO AR coating was found to be $6.81 \%$ corresponding to $J_{\mathrm{sc}}$ loss of $3.16 \mathrm{~mA} / \mathrm{cm}^{2}$ and this was further reduced to $3.42 \%$ corresponding to $J_{\mathrm{sc}}$ loss of $1.58 \mathrm{~mA} / \mathrm{cm}^{2}$ when additional layer of $\mathrm{LiF}$ was used. This is comparable to the values already obtained on textured wafers.

Figure 6 shows the total absorbance (1-reflectance) simulated for the optimized triple layer AR coating structure for our SHJ solar cell with nc-3C-SiC:H emitter. It is divided into several regions depending on the loss mechanism exhibited in each layer. This is to elucidate the dire importance of optimization of each layer in the overall short circuit current density that can be obtained from the SHJ solar cell.

When the thickness of $\mathrm{c}-\mathrm{Si}$ is varied from $200 \mu \mathrm{m}$ to $20 \mu \mathrm{m}$, there is an increase in reflection at longer wavelength $(\lambda>800 \mathrm{~nm})$. The reflection $J_{\mathrm{sc}}$ loss increases from $6.31 \mathrm{~mA} / \mathrm{cm}^{2}$ for $200 \mu \mathrm{m}$ thick wafer to $10.63 \mathrm{~mA} / \mathrm{cm}^{2}$ for $20 \mu \mathrm{m}$ thick wafer. This is because our triple AR coating concept on planar wafers fulfills only one function: optical enhancement by antireflection effect, which plays a fundamental role in the visible range of the spectrum. For textured wafers, a low reflection can be achieved over a broad wavelength range because front sides can fulfill two functions concerning the optical properties: first an antireflective effect and second a light path length enhancement by scattering or diffracting light into higher propagation angles. The light trapping effect cannot be realized by the front antireflective effect. However, it can be used in conjunction with other advanced light trapping schemes at the rear side, to enhance optical absorption in c-Si for near infrared wavelength, where penetration depth exceeds the cell thickness. We believe therefore that our triple layer AR coating designed here for the front side of the SHJ solar cell should be used in conjunction with plasmonic nanoparticles at the rear side or other rear side light trapping schemes to achieve a low reflectance over a broad wavelength of the visible light.

\subsection{Triple Layer AR Coating on an Encapsulated Flat SHJ} Solar Cell. For PV manufacturing processes, to provide protection for mechanical and electrical stability, the solar cell is encapsulated using ethyl vinyl acetate (EVA) and glass. This greatly influences the optical performance of the solar cell. Therefore to reflect real industrial PV application, the effect of triple layer AR coating in an encapsulated flat SHJ solar cell is investigated. Since the absorption in EVA and glass is not taken into account, we assume the glass and EVA structure has a thickness of $3 \mathrm{~mm}$ with refractive index of 1.5. As can be seen from Table 2, both the double layer and triple layer ARC structures lead to a reduction in $J_{\mathrm{sc}}$ under the encapsulation condition. When the solar cell is encapsulated, $\mathrm{LiF}$ needs to be further optimized. The optimized structure with a $\mathrm{LiF}$ thickness of $10 \mathrm{~nm}$ leads to $J_{\mathrm{sc}}$ of $36.78 \mathrm{~mA} / \mathrm{cm}^{2}$. This is still slightly higher than the double structure with only ITO and encapsulated double structure.

To achieve an effective optical interface, a selective material with a refractive index between 1.5 (EVA) and 2.0 (ITO) should be considered. Therefore use of dielectric material such as $\mathrm{Al}_{2} \mathrm{O}_{3}$ is highly recommended. As shown in Table 2, structure with $\mathrm{Al}_{2} \mathrm{O}_{3}$ shows $J_{\text {sc }}$ of $37.08 \mathrm{~mA} / \mathrm{cm}^{2}$.

\section{Conclusion}

We have demonstrated a triple layer antireflection design concept for planar SHJ solar cell that capitalizes on the transparent quality of nc-3C-SiC:H emitter. The antireflective effect of nc-3C-SiC:H is observed when one additional layer of dielectric is added to the SHJ structure with ITO to form a triple layer AR coating where nc-3C-SiC:H serves both 
as an emitter and AR coating. This leads to an appreciable reduction in reflection, with reflectance as low as 3.42\% for optimized thicknesses, at wavelength range of $300 \mathrm{~nm}$ to $1000 \mathrm{~nm}$. This, as confirmed with our studies, is not possible for the conventional SHJ based on a-Si:H emitter. The triple antireflective concept for the front side of $\mathrm{SHJ}$ solar cell investigated here can be used in conjunction with rear side light trapping plasmonic nanostructure schemes to achieve lower reflectance in thinner planar SHJ solar cells where texturing cannot be done. The parasitic absorption for the case of the optimized triple layer AR coating can be minimized when nc-3C-SiC:H emitter is used as compared to when a-Si:H emitter is applied. We conclude therefore that nc-3C-SiC:H is ideally suitable material for the emitter layer and design of triple layer AR coating for the front side of the planar thinner SHJ solar cell.

\section{Conflict of Interests}

The authors declare that there is no conflict of interests regarding the publication of this paper.

\section{Acknowledgments}

This work was partially supported by the New Energy and Industrial Technology Development Organization (NEDO) and Academy for Cocreative Education of Environment and Energy Science (ACEEES).

\section{References}

[1] K. Masuko, M. Shigematsu, T. Hashiguchi et al., "Achievement of more than $25 \%$ conversion efficiency with crystalline silicon heterojunction solar cell,' IEEE Journal of Photovoltaics, vol. 4, no. 6, pp. 1433-1435, 2014.

[2] M. Taguchi, A. Yano, S. Tohoda et al., " $24.7 \%$ Record efficiency HIT solar cell on thin silicon wafer," IEEE Journal of Photovoltaics, vol. 4, no. 1, pp. 96-99, 2014.

[3] Z. C. Holman, A. Descoeudres, L. Barraud et al., "Current losses at the front of silicon heterojunction solar cells," IEEE Journal of Photovoltaics, vol. 2, no. 1, pp. 7-15, 2012.

[4] S. Miyajima, M. Sawamura, A. Yamada, and M. Konagai, "Low temperature deposition of hydrogenated nanocrystalline cubic silicon carbide thin films by HWCVD and VHF-PECVD," in Proceedings of the IEEE 4th World Conference on Photovoltaic Energy Conversion, vol. 2, pp. 1604-1607, IEEE, Waikoloa, Hawaii, USA, May 2006.

[5] J. Irikawa, S. Miyajima, T. Watahiki, and M. Konagai, "High efficiency hydrogenated nanocrystalline cubic silicon carbide/ crystalline silicon heterojunction solar cells using an optimized buffer layer," Applied Physics Express, vol. 4, no. 9, Article ID 092301, 2011.

[6] S. Miyajima, J. Irikawa, A. Yamada, and M. Konagai, "Highquality nanocrystalline cubic silicon carbide emitter for crystalline silicon heterojunction solar cells," Applied Physics Letters, vol. 97, no. 2, Article ID 023504, 2010.

[7] K. Shimizu, A. E. Omondi, J. Irikawa, S. Miyajima, and M. Konagai, "Improvement of n-type nc-3C-SiC:H heterojunction emitter for c-Si solar cells," in Proceedings of the 40th IEEE
Photovoltaic Specialist Conference (PVSC '14), pp. 1253-1256, Denver, Colo, USA, June 2014.

[8] S. Miyajima, J. Irikawa, A. Yamada, and M. Konagai, "Modeling and simulation of heterojunction crystalline silicon solar cells with a nanocrystalline cubic silicon carbide emitter," Journal of Applied Physics, vol. 109, no. 5, Article ID 054507, 6 pages, 2011.

[9] ITRPV, International Technology Roadmap for Photovoltaic (ITRPV): 2013 Results, 2014.

[10] S. Tohoda, D. Fujishima, A. Yano et al., "Future directions for higher-efficiency HIT solar cells using a Thin Silicon Wafer," Journal of Non-Crystalline Solids, vol. 358, no. 17, pp. 2219-2222, 2012.

[11] S. Olibet, C. Monachon, A. Hessler Wyser et al., "Textured silicon heterojunction solar cells with over $700 \mathrm{mV}$ opencircuit voltage studied by transmission electron microscopy," in Proceedings of the European PV Solar Energy Conference and Exhibition (EUPVSEC '08), pp. 1140-1144, Valencia, Spain, September 2008.

[12] G. Li, Y. Zhou, and F. Liu, "Influence of textured c-Si surface morphology on the interfacial properties of heterojunction silicon solar cells," Journal of Non-Crystalline Solids, vol. 358, no. 17, pp. 2223-2226, 2012.

[13] M. G. Kang, S. Tark, J. C. Lee, C.-S. Son, and D. Kim, "Changes in efficiency of a solar cell according to various surface-etching shapes of silicon substrate," Journal of Crystal Growth, vol. 326, no. 1, pp. 14-18, 2011.

[14] Q. Wang, Y. Xu, E. Iwaniczko, and M. Page, "Light trapping for high efficiency heterojunction crystalline Si solar cells," ECS Transactions, vol. 34, no. 1, pp. 1129-1134, 2011.

[15] L. Fesquet, S. Olibet, J. Damon-Lacoste et al., "Modification of textured silicon wafer surface morphology for fabrication of heterojunction solar cell with open circuit voltage over $700 \mathrm{mV}$," in Proceedings of the 34th IEEE Photovoltaic Specialists Conference (PVSC '09), pp. 000754-000758, Philadelphia, Pa, USA, June 2009.

[16] S.-Y. Lien, C.-H. Yang, C.-H. Hsu, Y.-S. Lin, C.-C. Wang, and D.-S. Wuu, "Optimization of textured structure on crystalline silicon wafer for heterojunction solar cell," Materials Chemistry and Physics, vol. 133, no. 1, pp. 63-68, 2012.

[17] D. Jeong, C. Kim, J. Song et al., "Effect of texture morphology on the surface passivation and a-Si/c-Si heterojunction solar cells," in Proceedings of the 34th IEEE Photovoltaic Specialists Conference (PVSC '09), pp. 642-645, IEEE, Philadelphia, Pa, USA, June 2009.

[18] J. Eisenlohr, J. Benick, M. Peters, B. Bläsi, J. C. Goldschmidt, and M. Hermle, "Hexagonal sphere gratings for enhanced light trapping in crystalline silicon solar cells," Optics Express, vol. 22, no. 1, pp. A111-A119, 2014.

[19] J. Eisenlohr, H. Hauser, J. Benick et al., "Integrating diffractive rear side structures for light trapping into crystalline silicon solar cells," in Proceedings of the 28th European Photovoltaic Solar Energy Conference and Exhibition (EUPVSEC '13), Paris, France, 2013.

[20] J. He, C. Fan, J. Wang, Y. Cheng, P. Ding, and E. Liang, "Plasmonic nanostructure for enhanced light absorption in ultrathin silicon solar cells," Advances in OptoElectronics, vol. 2012, Article ID 592754, 8 pages, 2012.

[21] Y. Zhang, B. Jia, Z. Ouyang, and M. Gu, "Influence of rear located silver nanoparticle induced light losses on the light trapping of silicon wafer-based solar cells," Journal of Applied Physics, vol. 116, no. 12, Article ID 124303, 2014. 
[22] J. Park, N. Park, and S. Varlamov, "Optimum surface condition for plasmonic Ag nanoparticles in polycrystalline silicon thin film solar cells," Applied Physics Letters, vol. 104, no. 3, Article ID 033903, 2014.

[23] C. Hägglund, M. Zäch, G. Petersson, and B. Kasemo, "Electromagnetic coupling of light into a silicon solar cell by nanodisk plasmons," Applied Physics Letters, vol. 92, no. 5, Article ID 053110, 2008.

[24] F. J. Beck, A. Polman, and K. R. Catchpole, "Tunable light trapping for solar cells using localized surface plasmons," Journal of Applied Physics, vol. 105, no. 11, Article ID 114310, 2009.

[25] R. Stangl, M. Kriegel, and M. Schmidt, "AFORS-HET, version 2.2, a numerical computer program for simulation of heterojunction solar cells and measurements," in Proceedings of the IEEE 4th World Conference on Photovoltaic Energy Conversion, pp. 1350-1353, Waikoloa, Hawaii, USA, May 2006.

[26] E. O. Ateto, K. Shimizu, M. Konagai, and S. Miyajima, "antireflective effect of wide-gap heterojunction emitter for crystalline silicon heterojunction solar cell," in Proceedings of the 6th World Conference on Photovoltaic Energy Conversion (WPEC'14), Kyoto, Japan, November 2014.

[27] E. O. Ateto, M. Konagai, and S. Miyajima, "Optimum design of antireflection coating for heterojunction solar cell with nc-3CSiC:H emitter," in Proceedings of the 75th Japan Society of Applied Physics Conference, Hokkaido, Japan, 2014.

[28] J. Irikawa, S. Miyajima, T. Watahiki, and M. Konagai, "Development of the transparent conductive oxide layer for nanocrystalline cubic silicon carbide/silicon heterojunction solar cells with aluminum oxide passivation layers," Japanese Journal of Applied Physics, vol. 51, no. 2, Article ID 02BP04, 2012.

[29] S. Miyajima, M. Sawamura, A. Yamada, and M. Konagai, "Effects of hydrogen dilution ratio on properties of hydrogenated nanocrystalline cubic silicon carbide films deposited by very high-frequency plasma-enhanced chemical vapor deposition," Japanese Journal of Applied Physics, vol. 46, no. 25-28, pp. L693-L695, 2007.

[30] M. Victoria, C. Domínguez, I. Antón, and G. Sala, "Antireflective coatings for multijunction solar cells under wide-angle ray bundles," Optics Express, vol. 20, no. 7, pp. 8136-8147, 2012.

[31] J. Mouchart, "Thin film optical coatings. 1. Optical coating stabilities," Applied Optics, vol. 16, no. 9, pp. 2486-2490, 1977.

[32] D. Bouhafs, A. Moussi, A. Chikouche, and J. M. Ruiz, "Design and simulation of antireflection coating systems for optoelectronic devices: application to silicon solar cells," Solar Energy Materials and Solar Cells, vol. 52, no. 1-2, pp. 79-93, 1998.

[33] A. J. Bett, J. Eisenlohr, O. Höhn et al., "Front side antireflection concepts for silicon solar cells with diffractive rear side structures," in Proceedings of the 29th European PV Solar Energy Conference and Exhibition (EUPVSEC '14), Amsterdam, The Netherlands, September 2014. 

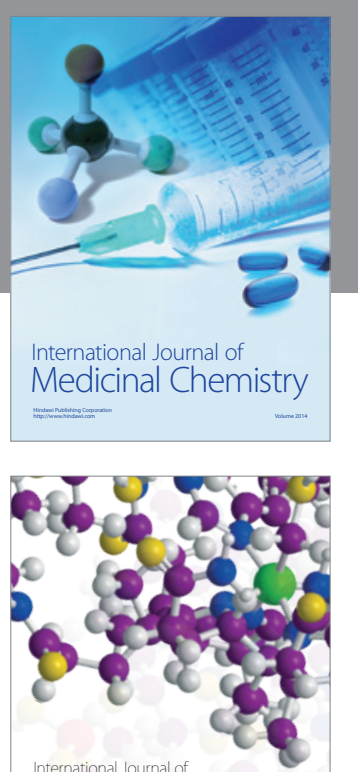

Carbohydrate Chemistry

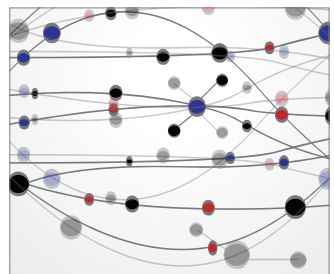

The Scientific World Journal
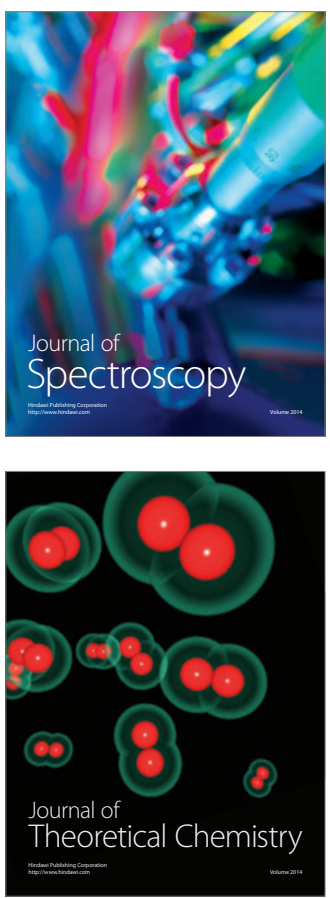
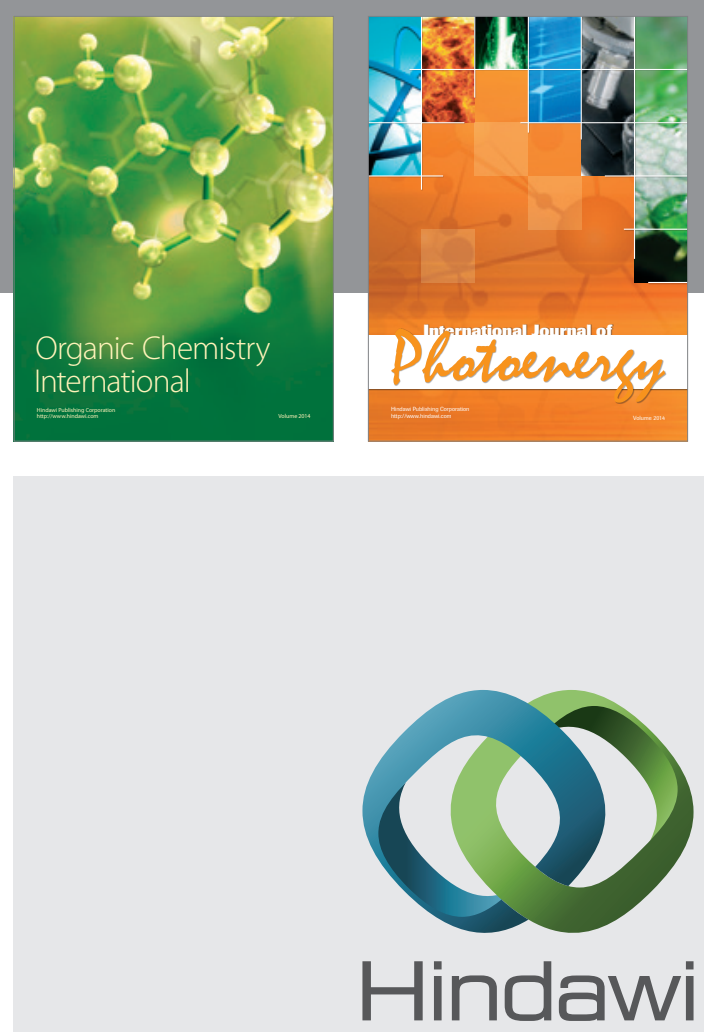

Submit your manuscripts at

http://www.hindawi.com

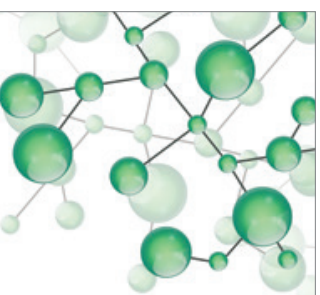

International Journal of

Inorganic Chemistry

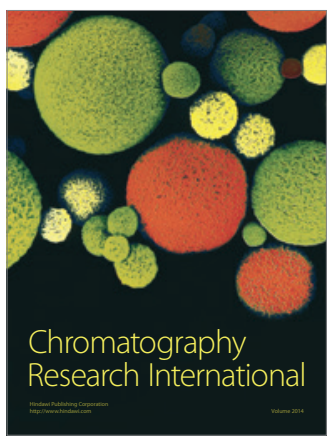

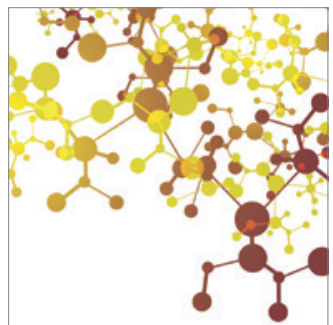

Applied Chemistry
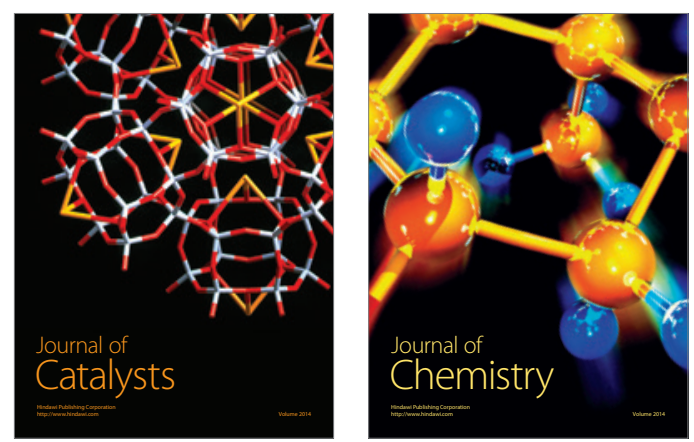
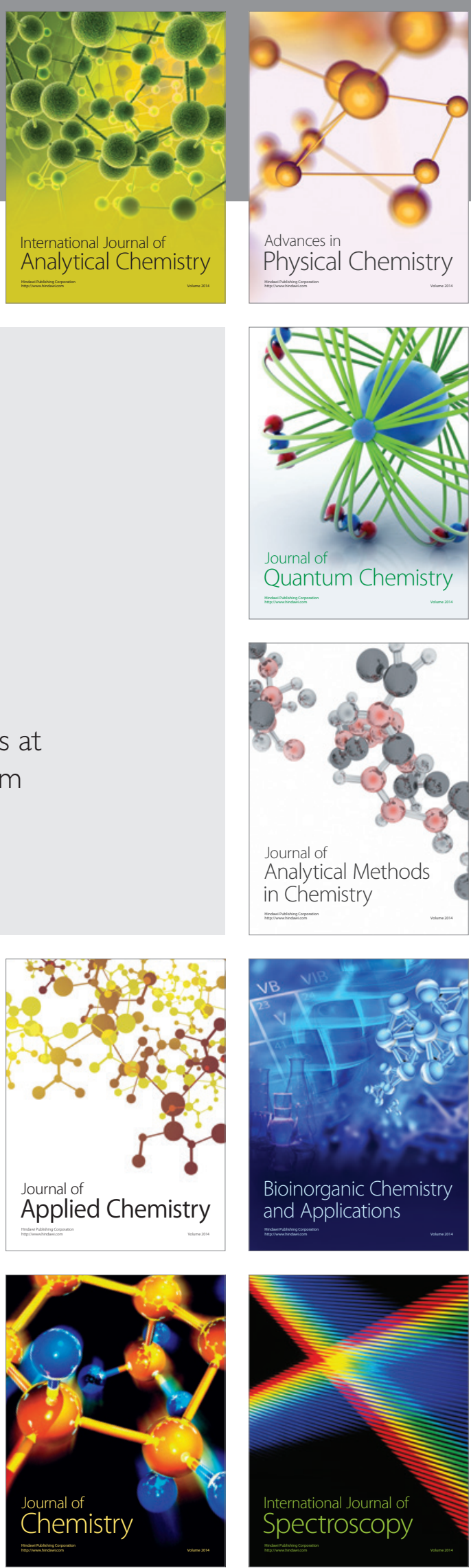